\title{
EXPLORATION OF ROTARY FRICTION WELDING TECHNIQUE
}

\author{
CHATHA Jagjeet Singh ${ }^{1 *}$, KOHLI Prabhsharan Singh², HANDA Amit ${ }^{3}$ \\ 1*Department of Mechanical Engineering, Punjabi University, Patiala, Punjab, India, \\ e-mail: erjagjeetsinghchatha@gmail.com \\ ${ }^{2}$ Department of Mechanical Engineering, Punjabi University, Patiala, Punjab, India \\ ${ }^{3}$ Department of Mechanical Engineering, IKG PTU, Kapurthala, Punjab, India
}

\begin{abstract}
Friction welding is a solid-state welding system which welds materials without authentic melting it. This study explores papers of different researchers on the friction welding method and it has been observed that the welding parameters like friction time; friction pressure, forge time and forge pressure highly affect properties of welded joints. The reason for this investigation is to exhort industry and the insightful world regarding advantages of revolving friction welding so the technique may be utilized in an ideal manner.
\end{abstract}

KEYWORDS: Friction, Forge, Solid-state, Micro-hardness.

\section{Introduction}

In recent years, many industries are opting for wide variety of material in their product for improving the performance and reducing the cost; due to this the demands to weld dissimilar metals have increased in a large scale. Friction welding is a solid state joining process which is used to join different number of metals. It can be used to weld metals of different mechanical properties (u.caligulu et al). In friction welding process one component rotates and pressure is applied relative to other mating component, due to this process heat is produced on the surfaces of the component and the softened material is forced out due to applied pressure. The weld is completed before or during an end of the process. It is the only method which is capable of joining dissimilar welds successfully having wide variety of mechanical properties. Main advantages of friction welding are low production cost, have the ability to weld dissimilar metals, high material saving (Handa.A et $a l)$. It is a welding which is capable of giving good quality welds.

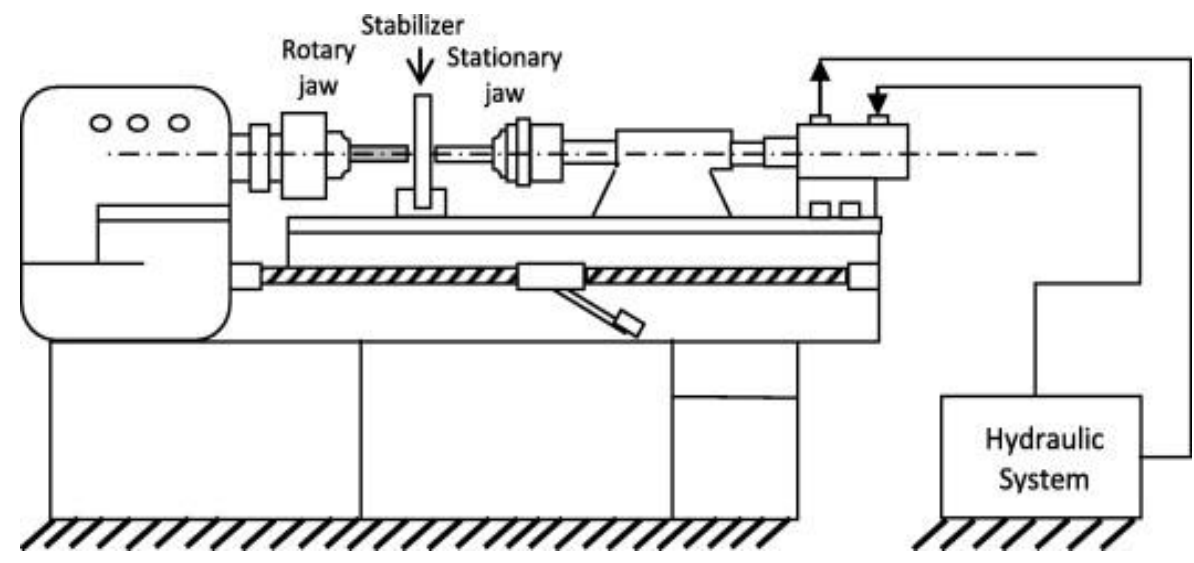

Fig. 1 Friction welding Setup (M.N.Ahmad fauzi et al.) 


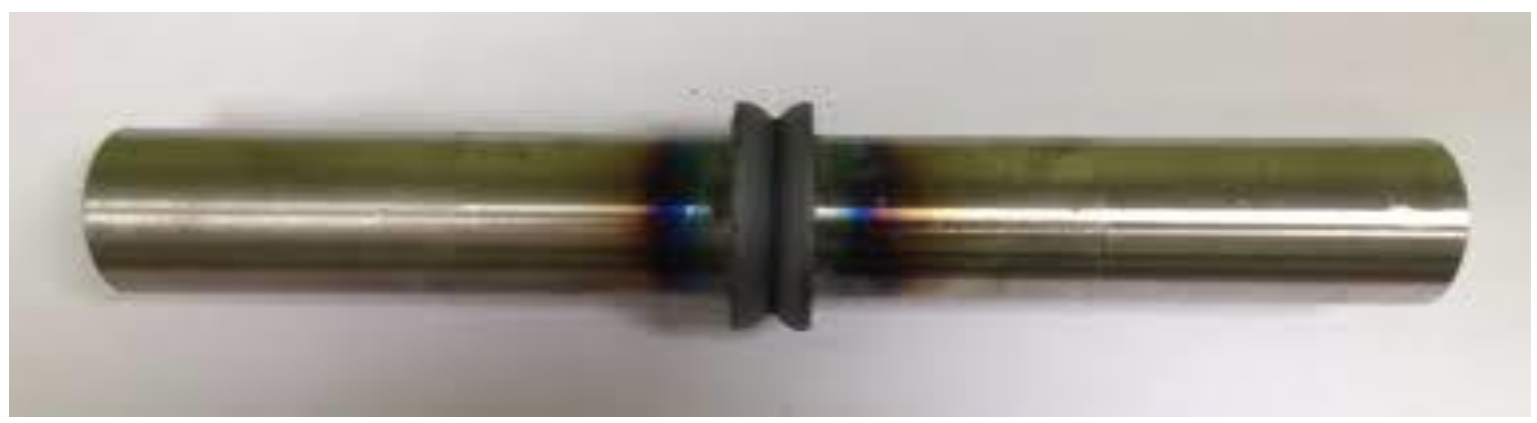

Fig. 2 Sample of prepared weld

\section{LITERATURE REVIEW}

Handa A. et al. (2014) investigated the characteristics of dissimilar steels AISI304 and AISI1021. The process parameters are rotational speed (800, 1000, 1250, 1430 and 1600rpm) and axial pressure (75-135MPa). Torsion, impact and micro hardness test were performed and the result was evaluated at (1430 rpm) and (130MPa) axial pressure maximum torsion strength was obtained. It is also observed that impact strength also increases due to increase in axial pressure, further it was found maximum at (1430rpm) and decreases with increased rotational speed. Inversed axial pressure or rotational speed contributes to increases in hardness. It was found maximum at (1600rpm) and (135MPa) axial pressure due to which it exceeds the $290 \mathrm{HV}$ value and the specimen fails without any deformation.

U.Caligulu et al. (2015) experimented rotary friction welding of AISI4340-AISI2205 steels on direct drive friction welding machines. The main process parameters were rotational speed (2200rpm), friction pressure (30MPa), forging pressure (60MPa), friction time $(6 \mathrm{~s})$ and forging time (3s). The welding joint was evaluated with microstructure, micro hardness and tensile strength test. The results proved that maximum tensile strength $(624.89 \mathrm{MPa})$ was achieved at (2200rpm) rotational speed. The microstructure changes shows different zones were formed at welding interface increased rotational speed and forging time decreases the wideness of deformed zone.

Pushpinder Singh et al.(2015) investigated mechanical characteristics of STELLITE-6 coated AISI3162 steel. Coating on specimen was done by detonation gun having various coated thickness ranging between $50 \mu \mathrm{m}$ to $150 \mu \mathrm{m}$. The effect of rotary friction welding process parameters were evaluated with the help of micro hardness, tensile strength and impact strength. It is found that on increasing stellite- 6 coating micro hardness and impact strength increased by $200 \%$ and $42 \%$ respectively of coated specimen than non-coated specimen, also tensile strength of coated specimen is found to be decreased by $7 \%$ which is negligible as compared to sudden increase in impact strength and micro hardness.

N.Ariuazhagan et al.(2014) investigated the mechanical properties of dissimilar metals AISI4140-AISI304. The process parameters used are friction force $(37.5 \mathrm{KN})$, upset force $(50 \mathrm{KN})$, rotational speed $(2500 \mathrm{rpm})$ and burn-off length $(5,7,9,12)$. The results were carried out with the help of microstructure, hardness and impact strength. It was found that increase in burn-off length increases hardness and decreases toughness. Also for maintaining the uniformity of microstructure optimum burn-off length should be kept which helps in decreasing the number of intermetallics. 
M.kimura at al.(2017) investigated the properties of rotary friction welding joint between pure aluminum and AISI304 stainless steel. Parameters such as friction speed (1650rpm), friction pressure (30MPa), friction time $(0.04-3.0 \mathrm{~s})$, forging pressure $(30-150 \mathrm{MPa})$ and forging time $(6 \mathrm{~s})$. Approximately $70 \%$ of joint efficiency is formed at friction time $0.6 \mathrm{sec}$ and approximately $80 \%$ of joint efficiency is formed at forge pressure of (150MPa). The joint had very little suffered area besides the region of CP-Al weld interface bend ductility of $90^{\circ}$ at these joints was obtained at forge pressure of (150MPa) and friction time of (1s) and no cracks were produced on the interface. Also because of decrease in tensile strength of CP-Al metals, joints didn't have $100 \%$ joint efficiency.

Niyazi Ozdemir et al.(2005) investigated different mechanical properties of rotary friction welded joint of hypereutectoid steels having $4 \% \mathrm{Al}$. The main parameters are friction pressure, forging pressure, friction time and rotational speed. It was found out that microstructure changes because the forged region got narrow due to viscous material being carried out because of increase in weld speed, forging and friction pressure. Micro hardness of the specimen was also tested, it was found that that micro hardness was maximum at all interfaces and varies at different rates toward the main material, the martensite formed in this region is due to effect of forging and friction time and pressure. During the tensile strength it was noted that after the rotary friction welding there was no plastic deformation in the specimen.

H.Fret Akala et al.(2003) experimented to weld steel by rotary friction welding technique. Tensile strength, micro hardness and microstructure test were performed and results were evaluated. The various optimum process parameters o carburizing steel were friction time $(5 \mathrm{~s})$, friction pressure (30 MPa), upset time (20 s), upset pressure (110 MPa). Tensile strength decreases when the width of the parts increased during welding because of increases in heat capacity and heat loss by rotation. During tensile test it was found that tensile strength was related to micro hardness due variation in heat affected zone (HAZ). In micro hardness test it was found that hardness increases in the horizontal direction and it is also seen that hardness decreases at welding lip. It varies within different region. In microstructure test it was seen that martensite structure due to which welded part did not become stronger.

M.N.Ahmad fauzi et al.(2009) investigated various mechanical properties of aluminum 6061 aluminum welded by rotary friction welding on a friction welding machines. The main process parameters was rotational speed $(1250,1800,2500 \mathrm{rpm})$. Microstructure, micro hardness and bending strength were performed and tests were evaluated. It was found in microstructure test that the best microstructure was found at 2500rpm rotational speed as compared to others rotational speeds, also three different zones were found at the weld interface i.e. unaffected zone, deformed zone and fully deformed zone. Micro hardness was also found out to be maximum at 2500rpm rotational speed. Hardness also increased due to decrease in grain size during plastic deformation bending strength was minimum at $1250 \mathrm{rpm}$ and maximum at $2500 \mathrm{rpm}$.

Billel cheniti et al.(2019) investigated micro structural changes of AISI 3042/c-CO cermet during rotary friction welding. The process parameters were friction time, upset time and upset pressure. Microstructure, tensile strength facts were performed and results were evaluated. It was found that tensile strength increased at maximum value with increases in forging time and pressure and after it detached maximum value it started decreasing with increases in forging time and 
pressure tensile strength was found maximum at friction time. In a microstructure test during the friction time of $4 \mathrm{~s}$ burn-off was the smallest with the increases in friction time of (12s), burn-off increases to $30 \%$. Also due to higher heat generation flash formation tool. Hence, it started from friction time of $8 \mathrm{~s}$ which leads to more waste deformation. It was found that micro hardness highest at low friction time as the friction time increases hardness went on decreasing. It was also seen that bonding strength was maximum at $8 \mathrm{~s}$ during the friction time of (4s) bonding strength was $290 \pm 35 \mathrm{MPa}$ and it increased by $75 \%$ and reached $525 \pm 35 \mathrm{MPa}$ at $8 \mathrm{~s}$ friction time.

Xun li et al.(2016) investigated mechanical properties of TC4/SUS321 joints by varying rotation speeds, the process was done on a continuous drive direct machine. The main process parameters were friction pressure (150 MPa), burn off length $(5 \mathrm{~mm})$, upsetting pressure (300 MPa), upsetting time $(10 \mathrm{~s})$ and rotation speed $(400,600,200,1500,1800 \mathrm{MPa})$. Various tests such as micro hardness, tensile strength and microstructure were carried out and results were evaluated. After welding of joints at different speeds it was observed that two regions were formed on TC4 side i.e. dynamic recrystallization zone (DRZ) and thermo-mechanically affected zone (TMAZ) and DRZ was found to be larger on TC4 side also width of DRZ decreases with increase in rotation speed. Max hardness of TC4 was found due to grain refinement obtained at higher rotation speed and on SUS321 side it almost remain unchanged as compared to TC4, max tensile strength was found to $465 \mathrm{Mpa}$ at $600 \mathrm{rpm}$ rotational speed and also strength decreases when the rotational speed increases above $600 \mathrm{rpm}$.

Peng Li et al.(2017) experimented rotating friction welding of Copper/Aluminium dissimilar joints and evaluated then, mechanical properties. The process was carried on a continuous drive friction welding machine. Various parameters were set as an upsetting pressure, friction speed, upsetting time, and friction pressure time. IT was seen that flash produced was at lower friction pressure $(6 \mathrm{MPa})$ as the friction pressure increases flash also increases and gives better appearance and also seen that heat generation depends on both friction time and friction pressure. The microstructure formed was found out to be strong at friction pressure (12 $\mathrm{MPa}$ ) and friction time of (12 s). Also the tensile strength of (35 MPa) was found to be max at friction time (12 s) and friction pressure of $(12 \mathrm{MPa})$.

Mumin Sahin(2005) experimented joining of high-speed steel and medium carbon steel by rotating friction welding; the process parameters were friction time, friction pressure, and friction speed. The weld joint was evaluated with different tests that are tensile strength, microstructure, and micro hardness. It was noted that with increases in friction time and friction pressure tensile strength increase and at some particular point strength started decreasing due to further increase in friction time and friction pressure. During the microstructure test it was found that burr was bigger on medium carbon steel side joints. Also it was found that hardness was obtained to be higher in the joints which were not annealed as compared to annealed joints at 650 degree $\mathrm{C}$ for $4 \mathrm{hrs}$. It was also noted that hardness mostly increased in the welding zone.

Mumin Sahin et al.(2007) investigated mechanical Characteristics of AISI1040 which were welded by rotary friction welding on a continuous drive friction welding machine. The main process parameters were rotation speed, friction pressure, friction time, upset time and upset pressure. The weld joint was evaluated with tensile, micro hardness testing. It was noted that tensile strength increases with the increase in friction time and pressure and further started decreasing at some particular point. It was also seen that hardness increases in the horizontal direction at the welding centre and in vertical direction it increases at the end part. 
Hazman Sel et al.(2010) investigated various characteristics of mild steel and aluminium by rotary friction welding. The main process parameters were rotational speed and axial force. Hardness, tensile strength tests were done and results were evaluated. It was found that hardness of the joints were lower as compared to their parent metal because of thermal effects of rotary friction welding. The tensile strength was also found to be low at (45 MPa) of joint which was lower than their parent metal. Less tensile strength and hardness was found due to incomplete welding.

P.D Sketchley et al. (2002) experimented rotary friction weld mechanical of Fe3Al based ODS alloys and also found out their Mechanical properties. The parameters were friction force, rotation speed, forge force and displacement. The welds were evaluated with tensile and microstructure testing. It was seen strength of parent metal was not achieved by ODS alloys because the microstructure was irreversible damaged at the bond line. It was also found that there was no difficulty in joining the welds. Also rotary friction welding process is found out to be better than fusion processes in joining the ODS joints.

SongYu-Lai et al.(2008) investigated the distribution of strength on aluminium and nodular cast iron due to rotary friction welding. Welds were obtained by using continuous direct drive machine. The parameters were friction pressure $(40 \mathrm{MPa})$, friction time $(6 \mathrm{~s})$, rotational speed $(300 \mathrm{rpm})$, forging pressure $(100 \mathrm{MPa})$ and forging time $(3 \mathrm{~s})$. Welds were evaluated with microstructure, tensile strength testing. It was seen that bond strength increased at the interface with increase of radii and after some point it started decreasing with increase of radii. Also it was found that due to intermetallic compound bond strength decreases. At the Central area there is less effect of intermetallic compound because of proper heat input.

A Varis et al.(1998) investigated various characteristics of rotary friction welding of titanium alloy. The main process parameters were friction pressure and friction time. It was noticed that welding conditions increased due to increase of frequency of oscillation, also it is seen that higher frequencies can be obtained at lower friction pressure to have higher power. Larger heat affected zones and higher strength was obtained at lower friction pressure as compared to higher friction pressure. It was also found that welding conditions can be improved at the end of the process by applying forging pressure.

Minjing Wang et al.(2019) experimented rotary friction welding of $\mathrm{CuCrZr} / 316 \mathrm{~L}$ and also found their mechanical properties. The main process parameters were rotating speed $(2500 \mathrm{rpm})$, friction force $(10 \mathrm{kN})$ and friction time $(1.2 \mathrm{~s})$, forge force $(10 \mathrm{kN})$ and forge time $(0.3 \mathrm{~s})$. Microstructure, micro hardness and tensile strength tests were performed and results were evaluated. It was seen that mostly the flash was produced on $\mathrm{CuCrZr}$ as compared to 316L. It was noted that hardness and tensile strength were increased at the interface because of the aging of as-welded specimen. Also some micro defects were found at the interface.

G.D Wen et al. (2014) experimented rotary friction welding of dissimilar joints Ti-6A1-4V and TI-b.5 Al-3.5Mo-1.5Zr-0.35i and also found there mechanical properties. The welds were evaluated with microstructure, micro hardness tests. It was seen that two zones were found that is weld zone (WZ) and thermo-mechanically affected zone (TMAZ), also it was seen that there is a large micro structural change occurred due to the martensite present in WZ and grains in TMAZ. Hardness was found to be highest in WZ. A highly durable joint was achieved by rotary friction welding because 
the weld line was far away from TC4 side as most of the fatigue failure was obtained on joining dissimilar metals.

Jinglong Li et al. (2014) investigated mechanical properties due to the effect of friction time on Ti6A14V/SUS321 metals. The main process parameters were friction speed $(1900 \mathrm{rpm})$, friction pressure $(184 \mathrm{MPa})$, upset pressure $(330 \mathrm{MPa})$, friction time $(1-4 \mathrm{~s})$. It was seen that by increasing friction time from $(1-4 \mathrm{~s})$, burn off length was increased and also higher tensile strength was obtained at $4 \mathrm{sec}$ friction time, mostly the burn off length was found at Ti6AL4V side. Microstructure changes at different friction times, concaved shape was seen at the interface also the dynamic recrystallization zone (Drz) becomes larger with increase in friction time. Hardness of the specimen increases in Drz, also it was found maximum near welded interface. It was also observed that shorter friction time leads to more surface fracture as compared to longer friction time. Also maximum strength was found at $560 \mathrm{MPa}$ at (4 s) friction time.

Amit Handa et al. (2016) experimented the joining of two dissimilar materials AISI304 and 1021 steels by friction welding. The specimens are welded under different friction forces ranges from 75 $\mathrm{MPa}$ to $135 \mathrm{MPa}$ and at constant rotational speed of $920 \mathrm{rpm}$. The tensile strength, torsional strength, impact strength, and micro-hardness tests are performed on the joints. They found that mechanical properties improved at high friction forces and forge pressure. During fractography analysis they observe ductile failures of welds at $120 \mathrm{MPa}$ and $135 \mathrm{MPa}$ axial forces.

\section{CONCLUSIONS}

- Important parameters which affect are forge time, forge stress, rubbing time and friction pressure.

- The tensile strength value of welded material at the joint increase with increase in rubbing time and forge stress values.

- The tensile value increase till critical point further it starts declining.

- No harmful emission is discharged during the process.

- The optimal variable must be chosen for the optimum results.

- Process is suitable to weld materials which are considered not suitable for traditional welding technique.

\section{DISCLOSURES STATEMENT}

The authors proclaim that there is no dispute on subject of publication of this paper.

\section{REFERENCES}

[1] Handa, A., Chawla, V. "An Investigation on the Effect of Axial Pressures on the Mechanical Properties of Friction Welded Dissimilar Steels", Advances in Mechanical Engineering 6, 639378, 2014. DOI: $10.1155 / 2014 / 639378$

[2] Caligulu, U., Yalcinoz, M., Kati, N., Balalan, Z., Islak, S. "The Effects of Rotation Speed and Friction Time for Joining of AISI 4340 - 2205 Steels by Friction Welding", Metallofiz. Noveishie Tekhnol 37 (5), pp. 665 - 681, 2015.

[3] Singh, P., Handa, A. "Mechanical Properties of Stellite-6 coated AISI 316L Stainless Steel", Materials Engineering 22, pp. 173 - 179, 2015.

[4] Arivazhagan N et al /Int.J. ChemTech Res. 6(1), pp 409 - 415, 2014. 
[5] Kimura, M., Suzuki, K., Kusaka, M., Kaizu, K. "Effect of friction welding condition on joining phenomena and mechanical properties of friction welded joint between 6063 aluminium alloy and AISI 304 stainless steel", Journal of Manufacturing Processes 26, pp. 178 - 187, 2017. DOI: 10.1016/j.jmapro.2017.02.008

[6] Ozdemir, Niyazi, Orhan, Nuri. "Microstructure and mechanical properties of friction welded joints of a fine-grained hypereutectoid steel with $4 \%$ Al", Journal of Materials Processing Technology - J Mater Process Technol. 166, pp., 63 - 70, 2005. DOI: 10.1016/j.jmatprotec.2004.07.095

[7] Şahin, M., Akata, H. E. "Joining with friction welding of plastically deformed steel”, Journal of Materials Processing Technology 142 (1), pp. 239 - 246, 2003. DOI: 10.1016/s09240136(03)00589-2

[8] Ahmad Fauzi, M. N., Uday, M. B., Zuhailawati, H., Ismail, A. B. "Microstructure and mechanical properties of alumina-6061 aluminum alloy joined by friction welding", Materials \& Design 31 (2), pp. 670 - 676, 2010. DOI: 10.1016/j.matdes.2009.08.019

[9] Cheniti, B., Miroud, D., Badji, R., Hvizdoš, P., Fides, M., Csanádi, T., Tata, M. "Microstructure and mechanical behavior of dissimilar AISI 304L/WC-Co cermet rotary friction welds", Materials Science and Engineering: A. 2019. DOI: 10.1016/j.msea.2019.04.081

[10] Li, X., Li, J., Liao, Z., Jin, F., Zhang, F., \& Xiong, J. "Microstructure evolution and mechanical properties of rotary friction welded TC4/SUS321 joints at various rotation speeds", Materials \& Design 99, pp. 26 - 36, 2016. DOI: 10.1016/j.matdes.2016.03.037

[11] Li, P., Li, J., Dong, H., Ji, C. "Metallurgical and mechanical properties of continuous drive friction welded copper/alumina dissimilar joints", Materials \& Design 127, pp. 311 - 319, 2017. DOI: $10.1016 /$ j.matdes.2017.04.093

[12] Sahin, M. "Joining with friction welding of high-speed steel and medium-carbon steel", Journal of Materials Processing Technology 168 (2), pp. 202 - 210, 2005. DOI: 10.1016/j.jmatprotec.2004.11.015

[13] Sahin, M., Akata, H. E., Gulmez, T. "Characterization of mechanical properties in AISI 1040 parts welded by friction welding”, Materials Characterization 58 (10), pp. 1033 - 1038, 2007. DOI: 10.1016/j.matchar.2006.09.008

[14] Seli, H., Ismail, A. I. M., Rachman, E., Ahmad, Z. A. "Mechanical evaluation and thermal modelling of friction welding of mild steel and aluminium", Journal of Materials Processing Technology 210 (9), pp. 1209 - 1216, 2010. DOI: 10.1016/j.jmatprotec.2010.03.007

[15] Sketchley, P., Threadgill, P., Wright, I. "Rotary friction welding of an Fe3Al based ODS alloy", Materials Science and Engineering: A 329 - 331, pp. 756 - 762, 2002. DOI: 10.1016/s0921-5093(01)01656-2

[16] Song, Y., Liu, Y., Zhu, X., Yu, S., Zhang, Y. "Strength distribution at interface of rotaryfriction-welded aluminum to nodular cast iron", Transactions of Nonferrous Metals Society of China 18 (1), pp. 14 - 18, 2008. DOI: 10.1016/s1003-6326(08)60003-5

[17] Vairis, A., Frost, M. "High frequency linear friction welding of a titanium alloy", Wear 217 (1), pp. 117 - 131, 1998. DOI: 10.1016/s0043-1648(98)00145-8

[18] Wang, M., Zhao, S., Wang, W., Li, Q., Luo, G.-N. "Preliminary results of CuCrZr/316L tubeto-tube junctions fabricated with rotary friction welding", Fusion Engineering and Design 148, 111275, 2019. DOI: 10.1016/j.fusengdes.2019.111275 
[19] Wen, G. D., Ma, T. J., Li, W. Y., Wang, S. Q., Guo, H. Z., \& Chen, D. L. "Strain-controlled fatigue properties of linear friction welded dissimilar joints between $\mathrm{Ti}-6 \mathrm{Al}-4 \mathrm{~V}$ and $\mathrm{Ti}-$ 6.5 Al-3.5Mo-1.5Zr-0.3Si alloys", Materials Science and Engineering: A 612, pp. 80 - 88, 2014. DOI: $10.1016 /$ j.msea.2014.06.010

[20] Li, P., Li, J., Salman, M., Liang, L., Xiong, J., Zhang, F. "Effect of friction time on mechanical and metallurgical properties of continuous drive friction welded Ti6Al4V/SUS321 joints", Materials \& Design (1980-2015) 56, pp. 649 - 656, 2014. DOI: 10.1016/j.matdes.2013.11.065

[21] Handa, A., \& Chawla, V. "Experimental Evaluation Of Mechanical Properties Of Friction Welded Dissimilar Steels Under Varying Axial Pressures", Strojnícky časopis - Journal of Mechanical Engineering 66 (1), pp. 27 - 36, 2016. DOI: 10.1515/scjme-2016-0008 